\title{
Xenía 3.0: Recreando la hospitalidad en un mundo diverso
}

\author{
Alberto Ares MATEOS* \\ Instituto Universitario de Estudios sobre Migraciones, \\ Universidad Pontificia Comillas (España) \\ alares@comillas.edu
}

\begin{abstract}
Resumen
El objetivo principal de este artículo es recrear la práctica de la hospitalidad en el contexto de la realidad migratoria actual, con la intención de aportar luz a la manera de gestionar la diversidad, de repensar la formación de identidad, de acercarnos a ciertas dinámicas políticas y últimamente de incentivar procesos de integración y cohesión social, especialmente en la vida de nuestros barrios. Para ello, el autor se adentra en las raíces bíblicas de la hospitalidad, aportando algunas claves para entender esta virtud hoy. En nuestro mundo actual donde parecería ganar terreno la hostilidad sobre la hospitalidad, la práctica de la hospitalidad constituye un auténtico acto de resistencia.
\end{abstract}

Palabras claves: hospitalidad, migración, diversidad, identidad, integración.

\section{Xenia 3.0: Recreating hospitality in a diverse world}

\begin{abstract}
The main aim of this article is to recreate the practice of hospitality in the context of the current migratory reality, with the intention of bringing light to the way of managing diversity, of rethinking identity formation, of approaching certain political dynamics and lately to encourage processes of integration and social cohesion, especially in our vulnerable neighborhoods. For this purpose, the author delves into the biblical roots of hospitality, providing some clues to understand this virtue today. In our current world where hostility over hospitality seems to gain ground, the practice of hospitality constitutes a genuine act of resistance.
\end{abstract}

Key words: hospitality, migration, diversity, identity, integration.

\footnotetext{
* Doctor en Migraciones Internacionales y Cooperación al Desarrollo por la Universidad Pontificia Comillas. Licentiate in Sacred Theology en Boston College; licenciado en Ciencias Económicas y Empresariales en la especialidad de Dirección Comercial (Universidad de Valladolid). Es autor de La rueca migratoria: Tejiendo historias y experiencias de integración (2017), Hijos e hijas de un peregrino. Hacia una teología de las migraciones (2017), Las Migraciones en las Fronteras en Iberoamérica (2016) y coordinador de la obra Conocer al vecino, juntar mundos: la comunidad marroqui en V alladolid (2012).
} 
"Si la migración es el crisol, entonces la hospitalidad es el catalizador que cristaliza la visión de un futuro diferente y lleno de gracia donde todos nos sintamos en casa".

\section{1. ¿POR QUÉ HABLAR HOY DE HOSPITALIDAD?}

Hospitalidad es según la RAE la "buena acogida y recibimiento que se hace a los extranjeros o visitantes", así como la "virtud que se ejercita con peregrinos, menesterosos y desvalidos, recogiéndolos y prestándoles la debida asistencia en sus necesidades." La palabra hospitalidad se traduce del latín hospitalitas y del griego filoxenía (Philipps, 2015; Rivera-Pagán, 2013).

La hospitalidad es casi tan antigua como la humanidad. Una de las primeras palabras en torno a la hospitalidad que aparece en papiros de la Grecia clásica es "xenía". Significaba un contrato de hospitalidad que hacían los reyes. Los contratantes escribían sus nombres en unas tablillas, luego las rompían por la mitad y cada uno guardaba una parte. El portador de esta tablilla podía reclamar la hospitalidad en cualquier momento. Pronto esta práctica llegó a las ciudades. La xenía, en el ámbito privado designaba a los regalos ofrecidos por los invitados al final de una comida ritual, con la cual renovaban la amistad y la hospitalidad (Stählin, 1967).

La hospitalidad hacia el extranjero alcanzó un importante valor jurídico diplomático y al mismo tiempo un significado religioso. Zeus protegía al extranjero que no poseía derechos legales y también al fugitivo que imploraba clemencia y auxilio. "El vínculo de amistad con un extraño se sellaba con un banquete ritual, donde el vino tenía un importante papel, entre otras cosas por los efectos que produce en quien lo toma" (Martín, 2007: 22). La hospitalidad es descrita por la literatura griega y más tarde por la latina. Obras como la Ilíada y la Odisea, de Homero, las Argonáuticas de Apolonio de Rodas, o las obras de Virgilio, Ovidio y Lucano, dan muestra de ello (Martín, 2007: 21-33).

La Biblia, como veremos, recoge esta tradición que atraviesa la historia de la Iglesia hasta nuestros días. Una práctica, la de la hospitalidad, que

1 ¿Por qué el título de Xenía 3.0: Recreando la hospitalidad en un mundo diverso? Intentamos actualizar la práctica de hospitalidad en nuestros días; una práctica tan antigua como la humanidad, documentada en los primeros papiros clásicos con la palabra Xenía. La web 3.0, por su parte, constituye el último estadio de evolución en el mundo digital, en el que se busca una web enfocada al bien común, a la integración universal de las personas y a una herramienta para el desarrollo sostenible (Piñeiro, 2019). Xenía 3.0, está llamada a recrear en la actualidad la hospitalidad dentro de un mundo diverso, en el cual la hospitalidad se presenta como una práctica contracultural, un auténtico acto de resistencia que busca el bien común. 
estuvo muy presente entre los primeros cristianos en tiempos de persecución, pero que poco a poco se fue profesionalizando, y dio lugar por ejemplo a los hospitales, a los hospicios y orfanatos, entre otros. Algunos autores piensan que fue en esta época cuando la Iglesia perdió un elemento importante en la conexión con las personas que se encontraban en los caminos, pues se pasó de una relación de horizontalidad, a otra de dador de servicios, donde se producía una asimetría entre el "huésped" y el profesional que acogía y recibía un salario por sus servicios (Pohl, 1999: 113114).

Comunidades como las del Arca, "L'Abri Fellowship", "Annunciation House", "Open Door Community", "Jubilee Partners", "Houses of Hospitality" de Catholic Worker (Pohl, 1999: 118), o últimamente las Comunidades de Hospitalidad [en adelante CoHo] (Ares, 2016) son sólo un ejemplo de una vuelta a la hospitalidad radical y el porqué es necesario hacernos hoy la pregunta por la hospitalidad.

\section{Pilares BÍBlicos DE LA hOSPITALIDAD}

La práctica de la hospitalidad que encontramos en los tiempos clásicos, de acoger y cuidar al extranjero, al que está de viaje, lo hallamos también en nuestra tradición bíblica. El mundo semita, en el cual la virtud de la hospitalidad era apreciada y practicada, marca de lleno el Antiguo Testamento (Byrne, 2000; Richard, 2000). De hecho, la hospitalidad recorre como un eje transversal toda la Biblia, así como a los santos padres y la historia de la Iglesia hasta la actualidad.

"La Biblia presenta la realidad migratoria como un elemento común en la historia de la salvación" (Ares, 2017a). En los textos bíblicos se presenta al Pueblo de Dios como un pueblo peregrino, en movimiento donde la hospitalidad es una práctica común.

Ya en el Génesis, Abraham (Gn 18, 1-5) ejerce la virtud de la hospitalidad, sin darse cuenta que estaba hospedando a ángeles (Hb 13, 2). Moisés, como refugiado, fue bien recibido por Reuel, después de ayudar a sus hijas para dar de beber a sus rebaños de ovejas (Ex 2, 15-22). El juez Salomón fue tremendamente acogedor con sus invitados (1 R 4, 22), del mismo modo que Jerjes (Est 1, 2-8) y Vasti (Est 1, 9). Jezabel fue hospitalario con 850 falsos profetas (1 R 18, 19). Asimismo, el pueblo de Israel continuó siendo acogedor (1 S 28, 21-25 y 2 R 4, 8-10). La ley bíblica determinaba amar y acoger a los extranjeros ( $\mathrm{Lv} 19,33-34)$. En todo el Antiguo Testamento se nos recuerda nuestras raíces como pueblo errante y peregrino: "Mi padre era un arameo errante" (Dt 26, 5).

Jesús vive la hospitalidad en el centro de su misión y se reconoce como un migrante (Mt 25, 31-46). Incorporaba a la mesa a las personas que se 
encontraban en el camino. Jesús practicó la hospitalidad de una forma muy clara cuando alimentó a las multitudes (Mt 14, 15-21y Mt 15, 32-38). Él mismo se convirtió en huésped en casa de fariseos (Lc 7, 36-50 y Lc 14, 114) o en la casa de Marta y María (Lc 18, 38-42). Jesús se invitó a la casa de un pecador, Zaqueo, y allí mismo recibió hospitalidad (Lc19, 5-10). Los discípulos de Emaús fueron hospitalarios con Jesús, aun cuando solo le reconocieron al partir el pan, al recibir hospitalidad (Lc 24, 29-32). Jesús enseñó sobre la hospitalidad con distintas parábolas como la del Samaritano (Lc 10, 30-37). Numerosas cartas del NT hablan de la hospitalidad e invitan a ser acogedores (Hch 13, 3; Rm 12, 13; 2 Jn y 3 Jn; 1 Pe 4, 9; 1 $\operatorname{Tm} 5,10)$.

Los Santos Padres recogen la virtud de la hospitalidad como uno de los grandes ejes de sus enseñanzas y homilías. San Agustín plantea que la hospitalidad enriquece tanto al huésped, como a la persona que acoge.

Nadie se envanezca porque acoge al inmigrante: Cristo lo fue. Mejor era Cristo acogido y socorrido que los que lo acogieron y socorrieron. Nadie, pues, hermanos míos, sea soberbio cuando socorre al pobre, ni diga en su espíritu: yo doy, él recibe; yo le admito en mi casa, él carece de techo. Acaso es más lo que tú necesitas. Quizá es justo aquel a quien acoges, y él necesita pan y tú verdad; él precisa techo y tú cielo; él carece de dinero y tú de justicia. (San Agustín, Sermones, sermón 239,4. en Ares, 2017a: 12)

En la actualidad, el Papa Francisco insta en múltiples ocasiones a practicar la hospitalidad hacia las personas refugiadas y migrantes, hacia a aquellas que se encuentran en el camino. "Recuerden que la auténtica hospitalidad es un profundo valor evangélico, que alimenta el amor" (Francisco, 2016).

Ocho rincones bíblicos desde los cuales acercarse a la hospitalidad:

\subsection{Mambré: La magia del encuentro (Gn 18, 1-5)}

El Señor se apareció a Abrahán junto a la encina de Mambré, mientras él estaba sentado a la puerta de la tienda en lo más caluroso del día. Alzó la vista y vio tres hombres frente a él. (Gn 18)

Abraham y Sara acogen a tres extranjeros y sin saberlo abren su hogar a unos ángeles. Fruto de esa generosa acogida, el Señor les bendice y obra el milagro: les da un hijo. Este pasaje pone el énfasis en la importancia de la acogida de los extranjeros, a los que están en el camino. El mismo Dios es acogido a través de ellos (Arterbury, 2005). 
En el relato bíblico, los extranjeros prosiguen su viaje hacia Sodoma y Gomorra. De una actitud de acogida se pasa a una actitud de hostilidad. Los habitantes de estas ciudades quieren aprovecharse de ellos. Solo Lot, sobrino de Abraham, les protege. En esta ocasión, la hostilidad hacia el extranjero es fuente de maldición. Así, las ciudades de Sodoma y Gomorra son destruidas, salvándose solo Lot y su familia (Gn 19).

En resumen, la xenofilia, la práctica de la hospitalidad es fuente de bendición, obrándose el milagro del nacimiento de una nueva vida -Abraham y Sara-, mientras que la xenofobia acarrea la maldición y la muerte - Sodoma y Gomorra- (Rivera-Pagán, 2013: 31-51).

2.2. No había sitio para ellos en la posada: El nacimiento de Jesús (Lc 2, 1-20)

Lo envolvió en pañales y lo acostó en un pesebre, porque no habia lugar para ellos en la posada. (Lc 2)

El fragmento del nacimiento de Jesús nos presenta a un Dios que se encarna en una realidad muy concreta. Belén, una pequeña aldea, lejos de la capital del Imperio y dentro de un pueblo sometido. Dios no se apoya en ningún privilegio humano, ni se ahorra dificultades.

Dios nace en un pesebre, sin hogar y a la intemperie, lejos de la tierra donde vivía su familia. Jesús se convierte en un refugiado cuando su familia sufre persecución política y tiene que huir a Egipto (Mt 2, 13-15). La Biblia no nos lo dice, pero no hay certeza de que la Sagrada Familia tuviera los documentos en regla para viajar y cruzar la frontera de Egipto.

Jesús nace fruto de un acto de hostilidad, nadie les abre la puerta de su casa, ni siquiera en la posada. Nace fuera de la ciudad, en una cuadra. Aquellos que dan la bienvenida a Jesús, que le ofrecen hospitalidad, son unos pastores, gente muy sencilla. La buena noticia, la salvación, es revelada a unos pastores. Ellos han sido los primeros evangelistas de la historia. "Te doy gracias, Padre, Señor del cielo y de la tierra, porque has escondido estas cosas a los sabios y entendidos, y se las has revelado a los pequeños. Sí, Padre, así te ha parecido bien" (Mt 11, 25).

Decía Ignacio de Loyola que "la amistad con los pobres nos hace amigos de Dios" (Carta a los jesuitas del colegio de Padua, 1547). Es desde esa clave donde la practica de la hospitalidad con los más vulnerables es buena noticia, y nos acerca a Dios. 
2.3. Dame de beber: La hospitalidad transforma la vida (Jn 4, 4-10)

Llega una mujer de Samaría a sacar agua y Jesús le dice: Dame de beber. (Jn 4)

El encuentro de Jesús con la Samaritana junto al pozo de Sicar, anota un elemento esencial: la práctica de la hospitalidad transforma nuestras vidas (Richard, 2000).

Jesús le pide a la mujer un signo de hospitalidad y de acogida: un simple vaso de agua. La samaritana no puede dar crédito a sus ojos y se resiste a causa de sus prejuicios culturales y religiosos. De hecho, le sorprende que Jesús no haya caído en la cuenta.

El encuentro permite que la Samaritana se convierta y se salve. Jesús es fuente de salvación. La hospitalidad y la acogida del extranjero conducen a la conversión y a la salvación. Es en esa acogida como la Samaritana se da cuenta quién es Jesús. El no rechazar lo distinto, el abrir nuestra puerta, el acoger lo nuevo, se convierte en condición de posibilidad para reconocer al Señor y alcanzar la salvación.

La hostilidad está anclada muchas veces en el recelo, los prejuicios (González, 2015). Es a través del otro, como Dios nos abre a su presencia y transforma nuestras vidas.

2.4. Marta y María: La hospitalidad nos invita a acompañar (Lc 10, 38-42)

Marta, estás inquieta y preocupada por muchas cosas, pero solo una es necesaria. María ha escogido la mejor, y nadie se la quitará. (Lc 10)

En la práctica de la hospitalidad, es importante tener presente el servicio a las personas, así como el acompañamiento y la escucha. Ambas actitudes son vitales en toda acogida y convivencia. Lo que ocurre muchas veces, con nuestros ritmos frenéticos, es que buscamos lo efectivo, lo cortoplacista, lo que se puede medir.

Marta se desvive en servir a Jesús, en hacer muchas cosas y tener todo a punto. Los quehaceres cotidianos la mantienen ocupada, absorta. Sin embargo, María acompaña a Jesús, le dedica tiempo a la escucha, a estar a su lado.

En las CoHo es muy importante generar espacios de escucha, de gastar el tiempo y la vida juntos. Espacios gratuitos en los que nos dedicamos un tiempo los unos a los otros, creciendo juntos y compartiendo la vida.

Evidentemente que no estamos contraponiendo la actitud de servicio, a la actitud de acompañamiento y de escucha. Ambas son importantes, 
pero Jesús nos recuerda un elemento muy importante en la práctica de la hospitalidad, que especialmente hoy necesitamos cuidar. ${ }^{2}$.

2.5. El buen samaritano: Una guía práctica sobre hospitalidad (Lc 10, 3037)

¿Cuál de estos tres piensas que demostró ser el prójimo del que cayó en manos de los ladrones? El que se compadeció de él. Anda entonces y baz tú lo mismo. (Lc 10)

En este pasaje Jesús nos muestra como practicar la hospitalidad de la mano de un pagano, de un extranjero, un samaritano que para el pueblo judío no pertenecía al Pueblo de la promesa. Nos fijaremos en algunos verbos y actitudes (Byrne, 2000).

Abrió los ojos. Para ser hospitalario hay que ser capaz de centrar nuestra mirada, de abrir los ojos a la realidad circundante. Una mirada que se fija en lo esencial. Pero, no basta sólo con mirar, sino entramos en escena, sino nos dejamos conmover por la realidad, si no intentamos ponernos en la piel de las otras personas.

Se acercó. La hospitalidad nos moviliza ante la realidad que viven los otros, nos invita a acercarnos. Como dice el refrán castellano: "El roce hace el cariño". Lo acogió, curó sus heridas. Acoger supone ponerse al servicio, atender las necesidades de los demás, intentar revertir el sufrimiento o la incomprensión.

Lo acompañó. Lo subió a su cabalgadura y lo llevo a un espacio seguro, donde recobrar fuerzas. Se comprometió, se convirtió en prójimo. La hospitalidad es una invitación a comprometernos con la vida de los demás y nos transforma en "prójimos".

2.6. Dadles vosotros de comer: Las comunidades de hospitalidad (Mt 14, 14-21)

Dadles vosotros mismos de comer. No tenemos aqui más que cinco panes y dos pescados. Traédmelos, les dijo Jesús. Todos comieron hasta quedar satisfechos, y los discípulos recogieron doce canastas llenas de pedazos que sobraron. (Mt 14)

2 Calory Café es un recurso de la Fundación Red Íncola en Valladolid al que acuden cada tarde más de cien personas migrantes -muchas de ellas sin hogar. En ese recurso, se proporcionaba café y algo de comer a las personas que acudían. Lo normal era ver a muchos voluntarios y voluntarias, desviviéndose por hacer el café y mantener todas las galletas y comida en orden, muchas veces en la cocina alejados de los propios migrantes. En las reuniones periódicas de voluntarios, era bueno recordarnos que lo más importante de aquel recurso no era solo tener el café a punto, sino pasar tiempo con la gente, escuchar sus historias, jugar juntos a las cartas o al dominó. 
La práctica de la hospitalidad es una invitación constante a ponernos en el lugar de los demás, a compadecernos y apostar por el servicio. Es una invitación: "Darles vosotros de comer". Los discípulos son invitados a crear una $\mathrm{CoHo}$, mejor dicho, a generar comunidades que multipliquen esa práctica de vida y salvación (Dube, 2014).

Es en la práctica de la hospitalidad donde se obra el milagro, donde nos sentamos a la mesa y se celebra la sobreabundancia. "La hospitalidad abre fronteras. Las CoHo transitan por nuevos caminos de revitalización de la vida en común, como un signo de anuncio del Evangelio. Se presentan como una invitación y una bocanada de aire fresco dentro de la Iglesia" (Ares, 2016: 7).

Las CoHo anticipan el Reino a través de la acogida y la hospitalidad. La necesidad y fragilidad nos ayuda a descubrir nuestros egoísmos y falsas certezas, y nos abre a un conocimiento de Dios que se nos hace presente en el encuentro con los demás, con las personas que están en el camino. Ese encuentro hace sacar lo mejor de nosotros mismos y nos invita a crear CoHo.

Los pobres son también maestros privilegiados de nuestro conocimiento de Dios; su fragilidad y sencillez ponen al descubierto nuestros egoísmos, nuestras falsas certezas, nuestras pretensiones de autosuficiencia y nos guían a la experiencia de la cercanía y de la ternura de Dios, para recibir en nuestra vida su amor, la misericordia del Padre que, con discreción y paciente confianza, cuida de nosotros, de todos nosotros. (Francisco, 2013)

2.7. Emaús: Descubriendo a Dios en un acto de hospitalidad (Lc 24, 1335)

Estando con ellos a la mesa, tomó el pan, lo bendijo, lo partió y se lo dio. Entonces se les abrieron los ojos y lo reconocieron, pero él desapareció. Al instante se pusieron en camino. (Lc. 24)

Como los discípulos de Emaús, muchas personas en todo el mundo y por diversas razones abandonan su hogar. Los de Emaús huyen desconsolados, después de ver asesinar a Jesús, en plena crisis de vida y de fe. Los de Emaús se ponen en camino y Jesús les sale al encuentro. Jesús entra en diálogo con ellos, intenta que inicien un proceso de reconciliación (Ares, 2017b), que relean su vida, desde el acontecimiento central de la Pascua. Pero lejos de comenzar una nueva relectura de resurrección en sus vidas, recriminan a Jesús: ¿Pero tú no te has enterado de nada? Jesús los mira a los ojos, pero ellos no le reconocen. El tránsito, tanto para los de Emaús, como para las personas que emigran voluntaria o involuntariamente, suele 
ser un auténtico calvario por la complejidad y la burocracia en los procesos legales.

Jesús invitaba a que los discípulos hicieran una reelaboración, una nueva narración de los recuerdos. Por eso les pregunta. De sobra sabía lo que había ocurrido en Jerusalén. Lo mismo que les ocurre a muchas personas migrantes. A veces el propio acceso a los recuerdos es difícil debido al trauma que los propios recuerdos han causado a los migrantes. Jesús se toma en serio la acogida, la hospitalidad. Por una parte, toma la iniciativa y por otra se deja acoger. La hospitalidad es bidireccional (Ares, 2018).

Pero es desde ese espacio seguro, desde esa nueva narrativa, sentados a la mesa, en el pan compartido donde los discípulos reconocen a Jesús, y encuentran sentido a sus vidas. Es el momento donde se da la verdadera resurrección, donde se convierten en nuevas criaturas. Dios nos lleva a un nuevo estado donde no se niega, ni se olvida el pasado, pero se pone en un nuevo marco que nos convierte a todos en "nueva creación" (2 Co 5, 17).

2.8. Pentecostés: Unidad en la diversidad (Hch 2, 1-13)

Todos fueron llenos del Espiritu Santo y comenzaron a hablar en diferentes lenguas. iTodos por igual los oímos proclamar en nuestra propia lengua las maravillas de Dios! (Hch 2)

La diversidad puede generar vida desde la práctica de la hospitalidad (Hch 2, 1-13) o generar división y hostilidad (Gn 11,1-9) ¿Cómo afrontar esta situación? No podemos seguir con recetas antiguas en tiempos nuevos. Esto es lo que ocurría en Babel, generando división y egoísmo.

Por otro lado, la diversidad puede vivirse según el espíritu de Pentecostés. Una diversidad que abre sus puertas y genera riqueza y esperanza. Los encontró reunidos y se obró el milagro. Es el Espíritu Santo el que posibilita que se dé el milagro de la hospitalidad, del entendimiento (Berryhill, 2005: 71-86). Personas que provienen de distintos contextos, con diferentes culturas, lenguas... Todos ellos siguen conservando sus particularidades, pero logran entenderse.

A veces se nos olvida, igual que a los discípulos, que en el milagro de la hospitalidad la iniciativa nos viene de Dios. Es el Espíritu el que posibilita crear espacios de entendimiento, de acogida común, donde se viva la unidad en la diversidad. 


\section{AlguNAS CLAVES PARA ENTENDER LA HOSPITALIDAD HOY}

\subsection{La fragilidad como puerta de entrada a la hospitalidad}

Esta hospitalidad se presenta como un valor humano y espiritualmente vital y conectado con la vulnerabilidad del ser humano que siempre requiere ser acogido y acoger al otro, que siempre precisa crear espacios habitables y abandonar contextos inhóspitos. (Boné, 2008: 110)

La realidad migratoria actual presenta una invitación a renovar y profundizar en una teología de las migraciones. La práctica de la hospitalidad dentro de la Doctrina Social de la Iglesia, desenmascara una retórica de la hostilidad, en muchos casos clasista y con un discurso nativista.

La DSI se enraíza en el bien común y en la dignidad de todos los seres humanos creados a imagen y semejanza de Dios, así como en la interdependencia e interconectividad de toda la humanidad. El documento magisterial Erga Migrantes Caritas Christi presenta a los migrantes como cocreadores de una fraternidad universal y presenta la hospitalidad y las migraciones como elementos intrínsecos a la naturaleza de la Iglesia. La hospitalidad representa una manera de vivir la misión de todo cristiano, con una vocación de peregrino hacia la casa del Padre (Campese, 2012; Martínez, 2007).

Como hemos visto anteriormente, la hospitalidad fue primero un modo de supervivencia, que presentaba un elemento de reciprocidad y la condición de posibilidad para encontrarse con Dios a través del extranjero (Koenane, 2018).

La hospitalidad se enraíza en una teología de la gracia y la gratuidad (Boné, 2016) nos evoca nuestra vulnerabilidad (Boné, 2008: 119-121) y el común recuerdo de haber sido extranjeros en tierra extraña, descendientes de un arameo errante. La hostilidad, muchas veces está anclada en nuestro pecado que nos lleva a acumular más, a vivir de la apariencia y que nos convierte en personas soberbias. Desde esta realidad, el miedo a perder unos privilegios, envueltos en dinámicas de exclusión y marginalidad, desenmascara la importancia de una hospitalidad radical.

Una hospitalidad radical que nos recuerda que Dios es acogida, rememorando el recuerdo de nuestra propia vulnerabilidad, como pueblo peregrino que se asienta en experiencias clave de exilio. El Señor de la Gloria muestra sus heridas (Jn 20,25). Dios escribe la historia de salvación a través de su fragilidad, de la fragilidad humana. "He escuchado el clamor de mi pueblo, dice el Señor" (Ex 3, 7). Con su fragilidad vino a buscarnos.

La hospitalidad nos invita a no tener miedo a la fragilidad que vivimos en nuestro mundo, pues es desde esa vulnerabilidad desde donde se nos 
hace presente Dios. "Sus heridas nos han curado" (1 P 2, 24). Solo hay diálogo de herido a herido, desde la fragilidad (García, 2011).

La gracia se presenta pues como central en la práctica de la hospitalidad, así como en una economía de la bendición, de la abundancia que desborda cualquier encuentro. Todos somos receptores de la bendición de Dios, y la hospitalidad se fundamenta en esa bendición o abundancia (Bretherton, 2017).

El poder transformador de la hospitalidad reorienta nuestras vidas hacia el servicio y nos acerca al camino, a los márgenes donde Dios sale al encuentro de nuestros hermanos y hermanas migrantes. Ese poder trasformador de la hospitalidad abre las puertas, salta los cerrojos y nos anima a tender puentes.

\subsection{La hospitalidad en un mundo diverso}

Nuestra vida es un continuo ir y venir, en el que recorremos y transitamos muchos caminos. Una de las grandes riquezas que nos recuerda hoy la hospitalidad es la diversidad. Una gran variedad de culturas, de acentos, de religiones, de alimentos, de interpretaciones de la realidad, etc. Una diversidad que a su vez plantea un reto a la convivencia, a la creación de identidad y a la construcción de una ciudadanía plural y abierta (Ares \& Iglesias, 2017).

Ante la pregunta, ¿podremos vivir juntos?, en muchas ocasiones nos movemos entre dos extremos. Los que ven en lo diverso una amenaza, y la única solución para la convivencia en un refuerzo de la identidad nacional y de las fronteras (hostilidad); y aquellos que descubren en la diversidad una oportunidad para nuestras sociedades plurales, en las cuales el acento se centra en la acogida y la integración, sentando las bases de una verdadera cohesión social (hospitalidad).

La dificultad de gestionar en la Unión Europea o Estados Unidos la realidad migratoria, la presión de refugiados y migrantes en nuestras fronteras, la guerra interminable en Siria, los conflictos en diversos barrios con alto grado de diversidad cultural de las grandes urbes del mundo, los continuos asesinatos de periodistas o políticos que defiende el estado de derecho y denuncian las injusticias, las maras y la violencia generalizada entre algunos colectivos... todas parecen señales de que no podemos vivir juntos. Parecería que el espíritu de Babel se hubiera apoderado de nosotros. $\mathrm{Y}$ escudados en estas señales sembramos de miedo y de odio nuestros contextos más cercanos, jugando el mismo juego de la violencia y de cerrar filas, en lugar de preguntarnos por las causas, intentando revertirlas.

De este modo, generamos mecanismos de exclusión, que asocian al pobre, al extranjero, al que es distinto a mí, como el terrorista o violento; 
en el fondo abriendo una brecha cada vez más acuciada entre ricos y pobres, entre "legales e ilegales", y así un largo etcétera. Todo para perpetuar un sistema que mantiene a un estrato social cada vez más pequeño controlando el poder económico, político y de manejo de la información, entre otros ${ }^{3}$.

Pero, aunque no salgan en los titulares de los periódicos hay personas que han revertido esta manera de comprender el mundo y la vida. Personas que no buscan la fuerza y la violencia como el camino a seguir en contraposición al miedo y el odio, que descubrieron en el encuentro, en la hospitalidad, en la integración, en la construcción de puentes y de vínculos, en el amor, un camino sólido para la convivencia social, para la gestión de la diversidad y para el desarrollo de la humanidad (Ares \& Fernández, 2018).

En nuestro mundo hay muchos signos de esperanza, de que la hospitalidad es posible, muchos más que de odio y violencia. Millones de padres y madres se levantan cada día buscando un futuro mejor para los suyos, millones de profesores, de educadores, buscan cómo generar una cultura crítica de la vida y de la realidad en sus alumnos, educando en el respeto y la diversidad, millones de médicos, policías, basureros, bomberos... intentan hacer de las ciudades, de los pueblos, espacios sanos, limpios, seguros donde convivir, encontrarnos y jugar en nuestras plazas... Millones de líderes políticos, religiosos, comunitarios, que se desviven por sus comunidades y feligreses, sumando en la arena pública, soñando y generando las bases de una ciudadanía inclusiva y de sociedades solidarias y hospitalarias, donde se respire paz (Bretherton, 2004).

\subsection{La hospitalidad como clave para la convivencia}

Hoy en día la práctica de la hospitalidad plantea serías preguntas a la construcción de identidad, elemento constitutivo en el desarrollo vital de

3 Hace unos años, en una institución del Servicio Jesuita a Migrantes en Madrid, el Centro Pueblos Unidos, decidimos encontrar una nueva ubicación de uno de los pisos para la acogida de jóvenes subsaharianos. Recogimos varios criterios y uno de ellos era que estuviera en un barrio "normalizado" del norte de Madrid. Tuvimos suerte y encontramos una buena localización, con espacios amplios, y un precio inmejorable. Después de hacer el traslado, nos visitaron unos vecinos. Nos dejaron helados: "Estos jóvenes no pueden vivir aquí. No es propio que vivan en este barrio, y por supuesto que no se les ocurra utilizar la piscina de la urbanización." Cuando vieron que no estábamos de acuerdo, comenzaron dando otro tipo de razones: "Estos jóvenes van a violar a nuestras hijas y así un largo etcétera que es mejor no nombrar". Tiempo complicado, de hablar con los chicos y de invitarles a ser extremadamente corteses con los vecinos. A las pocas semanas se tenían ganado al vecindario. 
la persona y de los colectivos (Ares, 2017a). Estas cuestiones se manifiestan en lo cotidiano, cuando convivimos. Dinámicas en las que se tejen procesos de identidad personal y colectiva, tendencias más estáticas y dinámicas (Shepherd, 2014).

Hace tiempo escuché una pequeña historia a un hombre marroquí en España. Me dio luz para comprender un poco mejor cómo construye una persona su identidad. Decía algo así:

Mi vida es como una casa que comienzo a construir al estilo marroquí. A medida que va pasando el tiempo y necesito más habitaciones, edifico más espacios al estilo español. Ambos habitáculos forman parte de la misma casa y se comunican con escaleras, comparten a veces mobiliario, utilidad, etc. Si quieres conocerme de verdad, yo te mostraré toda la casa. Primero te enseñaré la planta baja, que son mis raíces, pero si no te mostrará las nuevas habitaciones y te quedarás en el primer piso, no me conocerías de verdad. Yo camino y recorro mi casa constantemente. A veces me siento más cómodo en un lugar, otras veces en otro. Mi casa es un todo y no se entiende sin recorrer todos sus rincones, los más antiguos y los más modernos, los que suelo mostrar a todos y los que se conocen en la intimidad. En mi casa se pueden ver espacios que cumplen una función muy precisa, bien ordenados y convenientemente amueblados, junto a otros inacabados y que funcionan como sala multiusos. Algunos necesitan más luz y otros necesitan ser reformulados. Rincones donde afirmo mis raíces y otros donde conviven diferentes tradiciones. Todos en la misma casa, relacionándose, conviviendo. Mi casa inacabada es como mi identidad, mi persona. ¿Quién sabe si en un futuro no construiré un nuevo habitáculo aquí o allá? ¿̇ un nuevo piso?

Llama mucho la atención -por lo menos a mí- que en nuestros contextos occidentales "lo diverso" se ha convertido en "una patata caliente" en el ámbito político y social. ¿Por qué el populismo y el proteccionismo está tomando una relevancia tan grande en diversas sociedades como la estadounidense o en Reino Unido? ¿Y qué decir del aumento de la ultraderecha nacionalista en varios países europeos, entre ellos Francia, en algunos países de Europa del Este, incluso en España?

El miedo ante lo nuevo es algo que no podemos controlar. Podemos decir que es lícito sentir temor cuando salimos de nuestra zona de confort, cuando abrimos nuestro campo de acción, cuando gestionamos otras ideas, cuando compartimos con otros un mismo espacio, etc. Ante esa ansiedad, existen tendencias que buscan simplificar, caminando hacia un horizonte homogéneo y unidimensional. Miran sobre todo el corto plazo y una respuesta "fácil". Pero nos vamos dando cuenta que si construyendo muros, además de simplificar nuestra vida, ayudara a crecer como sociedad, este elemento sería la solución definitiva a la convivencia. De hecho, 
en la actualidad esta solución cortoplacista rompe aguas por todos lados. Lo queramos o no, la diversidad es algo constitutivo de nuestra existencia.

Una buena parte de la humanidad también se siente descartada o poco preparada para vivir la diversidad e interactuar en este mundo en constante cambio. Como si la realidad se impusiera, sin estar preparados para afrontar las oportunidades y los restos que nos plantea. Algunas personas se quejan de que las decisiones importantes se toman en las grandes urbes, de manos de una "élite urbana y cosmopolita", dejando de lado a miles de millones de personas en el camino. Esta dinámica va unida a una globalización económica y financiera que realmente "no conoce fronteras", que escapa a toda regulación con conexiones en diversos paraísos fiscales, y que además margina y atenta contra los derechos laborales de las personas, entre otros. En el fondo, estamos generando o propiciando un caldo de cultivo que deja en bandeja de plata a millones de personas que ante estos movimientos populistas.

Por si esto fuera poco, a algunos colectivos les ha tocado vivir de lleno esa diversidad (Madroñero, 2011; Deleixhe, 2018). En muchos casos sin estar del todo preparados para ello tanto por formación, como por conectividad, entre otras razones. Son muchas de estas comunidades las que sobrellevan en sus barrios un alto grado de diversidad cultural y étnica, con una precariedad ya enquistada en el ámbito social y económico. Además, es en estas comunidades donde los recortes de derechos sociales se han hecho más evidentes.

En ese contexto, existen muchas voces entre esa "élite cosmopolita" que dice que los inmigrantes se han ido y que no necesitamos invertir en integración y cohesión social. Lo que no comentan muchos de ellos es que viven en zonas exclusivas donde la presión migratoria o de exclusión es casi nula y donde sus hijos van a escuelas para élites. Por eso, ante cualquier brote de violencia o conflicto, lo más fácil es asociar migración con terrorismo y violencia. Lo que no dicen es que en España siguen viviendo casi 7 millones de personas que no han nacido en territorio nacional. Dos de esos millones de personas, ya con nacionalidad española. Por si esto fuera poco, los niveles de exclusión social han ido creciendo en estos últimos años entre los colectivos más desfavorecidos. ¿Y todavía tenemos cara en decir que no es prioritaria la integración y la gestión de la diversidad en aras a una cohesión social? ¿Seguiremos poniendo tiritas, sembrando miedo y construyendo muros como única solución? Por no decir nada, de las causas que generan muchos de los movimientos de personas, las guerras, las hambrunas, la violencia generalizada... ¿Dónde están los planes de Cooperación Internacional? ¿Quién genera muchos de estos desplazamientos de personas y las situaciones de fuerte vulnerabilidad? 
¿Seguiremos pensando que los nacionalismos proteccionistas y los muros son la solución? Tal vez a corto plazo puedan dar un respiro desde un punto de vista económico o financiero, pero a mi modo de ver, es pan para hoy y hambre para mañana. Edificar alambradas más altas, fosos más hondos, cerrar fronteras estoy convencido que no es la solución. Pero gestionar la diversidad plantea interrogantes que no podemos obviar. Nuestro mundo globalizado necesita reglas de juego a distintos niveles, que tomen en cuenta las necesidades y la voz del conjunto social. De otro modo, nunca saldremos del círculo vicioso de la exclusión, los conflictos, la pobreza y una huida hacia adelante de una élite mundial que vive en una burbuja inalcanzable para miles de millones de personas.

Todos, todos los muros caen, hoy, mañana, o dentro de cien años, pero todos caen. No es una solución. El muro no es una solución. Construyamos puentes y no muros. Puentes que nos permitan derribar los muros de la exclusión y la explotación. Pasemos de la cultura del rechazo a la cultura del encuentro. (Francisco, 2015)

Lo veamos más o menos claro, lo cierto es que estamos llamados a convivir y a entendernos. El Espíritu en Pentecostés nos dice que otro mundo es posible. Sería una pena no enriquecernos de lo diverso. Lo diverso nos abre a lo más esencial del ser humano. Cada persona va construyendo su identidad en relación con los demás, convirtiéndola en un ser único. Así, la diversidad se convierte en condición de posibilidad para la convivencia, para la recreación de una sociedad que es múltiple, abierta, flexible y compleja. Lo diverso en cierta manera es un horizonte, una cierta utopía, que se va haciendo cuerpo, camino, proceso y realidad (Ares \& Iglesias, 2017).

\section{COMUNIDADES DE HOSPITALIDAD COMO RESISTENCIA}

En nuestro contexto actual donde parecería ganar terreno la hostilidad sobre la hospitalidad, incluso en algunos ámbitos de iglesia y teológicos, la práctica de la hospitalidad constituye un auténtico acto de resistencia (Russell, Clarkson \& Ott, 2009).

Resistencia al estilo de Jesús. Una hospitalidad que rompió las barreras de su tiempo, puro/impuro, en un mundo que en ocasiones se presenta roto y resquebrajado, el cristiano es llamado a tender puentes saltando los límites de lo legal-ilegal, de lo puro-impuro, y de la inclusión-exclusión ya que "la hospitalidad tiene un gran pilar en la celebración y Jesús invita a su mesa a aquellos a los que la sociedad rechaza o demoniza" (Ares, 2017a: 26). 
Se hace necesario una vuelta a los orígenes de nuestra hospitalidad, una hospitalidad tan antigua como la misma humanidad, como lo atestigua la xenía. La hospitalidad recorre nuestra tradición bíblica y buena parte de la historia de la Iglesia. Hemos visto como la hospitalidad es fuente de bendición (Gn 18,1-5), nos acerca a Dios acompañando a las personas más vulnerables (Lc 2, 1-20), transforma nuestras vidas (Jn 4, 4-10), nos invita a comprometernos con la vida de los demás, en especial los más vulnerables (Lc 10, 30-37), nos anima a crear CoHo donde se anticipa el Reino (Mt 14, 14-21), donde se anima al acompañamiento (Lc 10, 38-42), y a generar espacios de encuentro en los que se hace posible el milagro de la reconciliación (Lc 24, 13-35). Una hospitalidad que es obra de Dios, en la cual es el Espíritu el que posibilita crear espacios de acogida común, de entendimiento, donde se vive la unidad en la diversidad (Hch 1, 1-13).

La hospitalidad en nuestros días nos habla de fragilidad y reciprocidad, del poder transformador de abrir nuestras puertas y de tender puentes. De vivir la fragilidad no como una amenaza, sino como un elemento esencial para el encuentro con Dios. También la hospitalidad hoy en día plantea un interrogante a nuestra creación de identidad, a la gestión de la diversidad, a nuestra manera de hacer política o de tratar la integración y cohesión social, incluso a la vida en nuestros barrios.

La práctica de la hospitalidad en la Biblia y las vidas de tantas personas en nuestras sociedades que son capaces de abrir sus puertas atestiguan que otro mundo es posible y que bien merece invertir en integración desde una mirada amplia, facilitando espacios de encuentro y una cultura de la inclusión (Carvalhaes, 2018). De hecho, en el ámbito teológico varias voces apuntan a que se hace necesario el desarrollo de una teología de la hospitalidad (Tavard, 2007; Hamington, 2010; Sweeden, 2015; Plaatjies van Huffel, 2019).

Por eso, todos los grandes retos sociales necesitan de una respuesta que ponga en el centro a las personas. La movilidad humana en nuestras sociedades necesita de una visión global que no se plantee desde políticas "parche", sino que atienda a la realidad migratoria en sus distintas fases: en los países de origen, en los países de acogida, en los países de tránsito y en los países de destino. La migración no es un problema, sino una oportunidad y una gran riqueza para nuestras sociedades envejecidas.

Lo cierto, es que muchos barrios de nuestras ciudades están viviendo la multiculturalidad a pasos agigantados, con un buen número de personas no preparadas para afrontarla y sin unos programas claros que apoyen la integración de los más vulnerables.

En nuestros barrios, hay jóvenes que se enfrentan a altos niveles de fracaso escolar y con tasas de desempleo alarmantes - agravados entre la población migrante. A mi modo de ver, estamos convirtiendo nuestros 
barrios en auténticos polvorines, sin futuro. ¿Cómo podemos vivir en este contexto la hospitalidad? (Barciela, 2019).

El contexto político tampoco parece favorecer la práctica de la hospitalidad. Una realidad política cada vez más polarizada, y donde la realidad sentida, el terreno emocional, ha desplazado a la discusión ideológica. Las redes sociales viralizan en muchas ocasiones datos no contrastados o incluso falsos (fake news). Da la impresión de que la distancia ideológica entre partidos, sean muchos o pocos, ha crecido en las últimas décadas. Esta tendencia se explica debido al desplazamiento de algunos partidos tradicionales, pero sobre todo por la aparición de nuevos partidos que retan al sistema desde posiciones más extremas.

Muchos de estos elementos constituyen una seria amenaza a la democracia liberal. La gestión de disensos políticos debería de ser compatible con respecto al acuerdo a los procedimientos, a las formas y ciertos principios básicos. Dentro de la democracia liberal estos procedimientos son el voto, el reconocimiento de la legitimidad del adversario político, la libertad de información, de expresión y de protesta, la posibilidad de llegar a acuerdos con quienes no se comparte los mismos proyectos políticos y el respeto de los derechos de las minorías, entre otros. Cuando negamos o limitamos estos principios de los cuales nos hemos dotado, estamos violando el marco de juego o suelo común de la democracia liberal.

Cuando favorecemos la polarización afectiva, estas violaciones al marco de juego no son exactamente simétricas. En general, existen los que toman la parte por el todo y creen que su visión es la única legítima y admisible para el país y para la democracia. Son aquellos mismos que toman iniciativas de descrédito, desprecio y que incitan al odio y al miedo. Esta tendencia se suele agravar cuando desde las instituciones se sobrerreacciona, o se utiliza la fuerza de forma desproporcionada, limitando la diversidad, la pluralidad y la expresión pacífica de la divergencia.

Es en este contexto donde la hospitalidad se presenta con un elemento contracultural, de resistencia, apuntando que otro mundo es posible. La cálida acogida a migrantes y desplazados, a los que están en el camino, es uno de los pilares de una sociedad verdaderamente humana, que debe protegerse mediante políticas y ordenamientos jurídicos.

Las CoHo son espacios de encuentro, hogares donde conviven personas de contextos diversos, en las cuales tienen un lugar privilegiado aquellas personas que se encuentran en el camino. Comunidades que comparten techo y proyecto vital, generando procesos, desde la escucha mutua y el aprendizaje compartido.

En las CoHo se comparte la mesa con personas excluidas, cultivando una cultura del encuentro. 
Vivir a su lado es uno de los principales signos de la Buena Noticia, especialmente en una época como la actual en la que el individualismo erosiona las relaciones mutuas y la exclusión social priva a numerosas personas del reconocimiento y la amistad de los demás, así como de su dignidad humana. (Ares, 2016: 5)

Como nos recordaba la Biblia, la práctica de la hospitalidad en las CoHo produce un efecto transformador tanto en el huésped como en la persona que acoge. Siempre que miramos con los ojos del corazón, sin prejuicios, somos capaces de enriquecernos, de mirar con más cariño las realidades complejas y frágiles, de aprender de la diversidad. Vemos en esta diversidad una oportunidad para crecer juntos.

Las CoHo generan espacios de encuentro, entornos seguros, con un ritmo de vida en común que posibilita la convivencia en lo cotidiano, tiempos gratuitos de escucha, de reparto de tareas, de compartir las penas y alegrías. Todos son elementos que facilitan procesos de sanación, integración y reconciliación.

Mi experiencia personal es que las personas migrantes son portadoras de esperanza. Esperanza de un mundo en paz, de que es posible una vida mejor. Buscan seguridad y trabajo, pero, sobre todo, reconocimiento y respeto. Una sociedad que se cierra sobre sí misma se empobrece. Una sociedad que se abre a la posibilidad del encuentro y a la diversidad, se enriquece, construye futuro. Esta es una de las grandes claves que aporta la hospitalidad a nuestro mundo actual (Wrobleski, 2012).

Ante la pregunta, ¿podremos vivir juntos? Yo estoy convencido de que sí. De hecho, ya lo venimos haciendo desde hace tiempo, pero tenemos que tomarnos en serio el valor de la hospitalidad, invirtiendo en revertir las causas que provocan estos grandes movimientos forzados de personas, pero sobre todo en integración y en cohesión social.

Las $\mathrm{CoHo}$, en cuanto contraculturales, constituyen auténticos espacios de resistencia y anticipan el Reino cuando invitan a sentarse juntos en la misma mesa, a compartir lo que nos une y también desde la diferencia. En definitiva, las CoHo son una invitación a ser testigos de esperanza.

\section{REFERENCIAS}

Ares, A. (2016). Comunidades de Hospitalidad. Madrid: Jesuitas Social. Disponible en https://socialjesuitas.es/documentos/send/9-comunidades-de-hospitalidad/4-comunidades-de-hospitalidad

Ares, A. (2017a). Hijos e bijas de un peregrino. Hacia una teologia de las migraciones. Barcelona: Cristianisme i Justicia n. 206. Disponible en https://www.cristianismeijusticia.net/sites/default/files/pdf/es206.pdf

Ares, A. (2017b). Reconciliación y migraciones. Promotio Iustitiae, 124(2), 37-43. 
Ares, A. (2018). El oficio de reconciliar a los que están en el camino. Revista de Fomento Social, (287-288), 572-578.

Ares, A. \& Fernández, M. (2018). Toward a mixed integration model based on migrants'self-perception. Studi Emigrazione, (212), 633-656.

Ares, A. \& Iglesias, J. (2017). La integración social de la población refugiada desde la perspectiva teológica y sociológica. Estudios Eclesiásticos, 92(361), 217-247.

Arterbury, A. E. (2005). Entertaining angels: Early Christian hospitality in its Mediterranean setting. New Testament Monographs. Volume 8. Series editor Stanley E. Porter. Sheffield, UK: Sheffield Phoenix Press.

Barciela, S. (2019). Arde la ciudad. Conflicto en barrios. Madrid: Universidad Pontificia Comillas.

Berryhill, C. M. (2005). From dreaded guest to welcoming host: hospitality and Paul in Acts. En W. Lewis \& H. Rollmann (Eds.), Restoring the first-century church in the twenty-first century: essays on the Stone-Campbell Restoration Movement in honor of Don Haymes (pp. 71-86). Eugene, Oregon: Wifp and Stock Publishers.

Boné, I. (2008). Vulnerables y hospitalarios. Espiritualidad ignaciana y alteridad. Manresa: Revista de Espiritualidad Ignaciana, 80(315), 109-124.

Boné, I. (2016). Psicología de la gratitud y Ejercicios Espirituales. Manresa: Revista de Espiritualidad Ignaciana, 88(349), 385-398.

Bretherton, L. (2004). Tolerance, education and hospitality: A theological proposal. Studies in Christian Ethics, 17(1), 80-103.

Bretherton, L. (2017). Hospitality as holiness: Christian witness amid moral diversity. Routledge.

Byrne, B. (2000). The Hospitality of God: A Reading of Luke's Gospel. Collegeville, MN: Liturgical Press.

Campese, G. (2012). The irruption of migrants: theology of migration in the $21 \mathrm{st}$ century. Theological Studies, 73(1), 3-32.

Carvalhaes, C. (2018). We Are All Immigrants! Imago Dei, Citizenship, and The Im/Possibility of Hospitality. Practical Matters Journal, (11), 181-197.

Deleixhe, M. (2018). Démocratie et hospitalité. SociologieS. Disponible en http://journals.openedition.org/sociologies/6857

Dube, Z. (2014). Welcoming outsiders: The nascent Jesus community as a locus of hospitality and equality (Mk 9:33-42;10:2-16). In die Skriflig/In Luce Verbi, $48(1), 1-7$.

Francisco (2013). Visita al "Centro Astalli" de Roma para la asistencia a los refugiados. 10 de septiembre. Disponible en http://www.vatican.va/content/francesco/es/speeches/2013/september/documents/papa-francesco_20130910_centro-astalli.html

Francisco (2015). Todos los muros caen, hoy, mañana, o dentro de cien años, pero todos caen. No es una solución a la crisis migratoria. Disponible en https://www.periodistadigital.com/cultura/religion/vaticano/20150928/f rancisco-muros-caen-hoy-manana-o-cien-anos-caen-solucion-crisismigratoria-noticia-689400276979/ 
Francisco (2016). La auténtica hospitalidad es un profundo valor evangélico, SIC Agencia. Disponible en https://www.agenciasic.es/2016/09/19/papafrancisco-la-autentica-hospitalidad-es-un-profundo-valor-evangelico/

García, J. A. (2011). Ventanas que dan a Dios: experiencia bumana y ejercicio espiritual. Santander: Sal Terrae.

González, M. (2015). De la hostilidad a la hospitalidad, Cristianisme i Justicia, n. 196.

Hamington, M. (2010). Toward a theory of feminist hospitality. Feminist Formations, 22(1), 21-38.

Koenane, M. L. J. (2018). Ubuntu and philoxenia: Ubuntu and Christian worldviews as responses to xenophobia. HTS Teologiese Studies/Theological Studies, 74(1).

Madroñero, M. (2011). Alterity, Politics and Hospitality. Escritos, 19(43), 315-335.

Martín, C. (2007). Vino, banquete y hospitalidad en la épica griega y romana. Revista de filología románica, (5), 21-33.

Martínez, J. (2007). Ciudadanía, migraciones y religión: un diálogo ético desde la fe cristiana. Madrid: Universidad Pontificia Comillas.

Philipps, K. (2015). Hospitality and Emerging Populations: Toward a Theology of Migration in the Context of the Catholic Church in the United States. University of Toronto (Doctoral dissertation).

Piñeiro, G. (2019). La realidad de la web 3.0. Harvard Deusto Márketing y Ventas, (153), 6-11.

Plaatjies van Huffel, M. (2019). Toward a Theology of Hospitality: Statelessness as Gender Discrimination as a Challenge to Just Hospitality. Ecumenical Review, 71(4), 516.

Pohl, C. D. (1999). Making room: Recovering hospitality as a Christian tradition. Grand Rapids: Eerdmans.

Richard, L. (2000). Living the Hospitality of God. Mahwah, NJ: Paulist Press.

Rivera-Pagán, L. N. (2013). Xenophilia or Xenophobia: Toward a Theology of Migration. In Contemporary Issues of Migration and Theology (pp. 31-51). New York: Palgrave Macmillan.

Russell, L. M., Clarkson, J. S., \& Ott, K. M. (2009). Just hospitality: God's welcome in a world of difference. Westminster John Knox Press.

Shepherd, A. (2014). The gift of the other: Levinas, Derrida, and a theology of hospitality. Casemate Publishers.

Stählin, G. (1967). Hospitality. En G. Kittel and G. Friedrich (Eds.), Theological Dictionary of the New Testament (Translated and edited by G. W. Bromiley; Vol. 5: 21-23). Grand Rapids, MI: Wm. B. Eerdmans.

Sweeden, N. B. (2015). Church on the way: Hospitality and migration. Eugene, Or.: Wipf and Stock Publishers.

Tavard, G. H. (2007). A Theological Exploration of Ecumenical Hospitality. Ecumenical Review, 59(2/3), 242-256.

Wrobleski, J. (2012). The limits of hospitality. Liturgical Press. 